Pacific Journal of Mathematic 


\title{
ON THE RATIO ERGODIC THEOREM FOR SEMI-GROUPS
}

\author{
H. Fong AND L. Sucheston
}

\begin{abstract}
For a semi-group $\Gamma$ of positive linear contractions on $L_{1}$ of a $\sigma$-finite measure space $(X, \mathscr{A}, \mu)$, strongly continuous on $(0, \infty)$, there are two ratio ergodic theorems: one, due to Chacon and Ornstein, describes the behavior at infinity; the other one, due to Krengel-Ornstein-Akcoglu-Chacon, describes the "local" behavior. In the present paper we attempt to generalize these results to the case when the semigroup is only uniformly bounded. Then the space $X$ decomposes into two parts, $Y$ and $Z$, called the remaining and the disappearing part, and both ratio theorems are shown to hold on $Y$. The ratio theorem at infinity fails on $Z$.
\end{abstract}

This generalizes the situation described in the discrete case by the second-named author, and by A. Ionesen Tulcea and M. Moretz. We have not studied the "local" behavior of the ratio on $Z$.

1. Definitions. Let $\Gamma=\left\{T_{t}: t \geqq 0\right\}$ be a semi-group of positive linear operators in $L_{1}$ of a $\sigma$-finite measure space $(X, \mathscr{A}, \mu)$. We assume that $\Gamma$ is bounded: $\sup _{t>0}\left|T_{t}\right|_{1}<\infty$; and that $\Gamma$ is strongly continuous on $(0, \infty)$ : i.e., for each $f \in L_{1}$ and each $s>0$, we have $\lim _{t \rightarrow s}\left|T_{t} f-T_{s} f\right|_{1}=0$. It is then known (cf. [5], p. 616) that $\Gamma$ is strongly integrable on every interval $[\alpha, \beta], 0 \leqq \alpha<\beta<\infty$; more precisely, for each $f \in L_{1}$ and $0 \leqq \alpha<\beta<\infty$, the integral $\int_{\alpha}^{\beta} T_{t} f d t$ is defined and is an element of $L_{1}(X, \mathscr{A}, \mu)$. Hence for each $f \in L_{1}$ there is a scalar function $T_{t} f(x)$, measurable with respect to the product of Lebesgue measure and $\mu$, such that for almost all $t, T_{t} f(x)$, as a function of $x$, belongs to the equivalence class $T_{t} f([5]$, p. 686). Moreover, there is a set $E(f), \mu(E(f))=0$, dependent on $f$ but independent of $t$, such that if $x \notin E(f)$ then $T_{t} f(x)$ is integrable on every finite interval $[\alpha, \beta]$ and the integral $\int_{\alpha}^{\beta} T_{t} f(x) d t$, as a function of $x$, belongs to the equivalence class $\int_{\alpha}^{\beta} T_{t} f d t$. Thus for each $u>0$ and each $f \in L_{1}$, the integral $\int_{0}^{u} T_{t} f(x) d t$, denoted $S_{u} f(x)$, is defined for every $x \notin E(f)$.

All sets introduced in this paper are assumed measurable; all functions are measurable and extended real-valued. All relations are assumed to hold modulo sets of $\mu$-measure zero. The indicator function of a set $A$ is written $1_{A}$. We write $\operatorname{supp} f$ for the set of points at which the function $f$ is different from zero. For a set $A \subset X, L_{1}(A)$ denotes the 
class of functions $f$ in $L_{1}(X)$ with $\operatorname{supp} f \subset A ; A$ is said to be closed (under $T$ ) if $T\left\{L_{1}(A)\right\} \subset L_{1}(A)$.

2. Behavior at infinity. The following Theorem 2.1 is a continuous parameter version of the Chacon-Ornstein theorem; Theorem 2.1 is included in a result of Berk [3], and was also recently obtained by Akcoglu and Cunsolo [2]. The following proof shows that the result is in fact contained in that of [4].

TheOREM 2.1. Let $\Gamma=\left\{T_{t}: t \geqq 0\right\}$ be a semi-group of positive linear contractions in $L_{1}$ such that $\Gamma$ is strongly continuous on $(0, \infty)$. Let $f, g \in L_{1}, g \geqq 0$. Then, as $u \rightarrow \infty$, the ratio

$$
D_{u}(f, g)(x) \stackrel{\text { def }}{=} S_{u} f(x) / S_{u} g(x)
$$

converges to a finite limit a.e. on the set

$$
A(g) \stackrel{\text { def }}{=}\left\{x: \sup _{u>0} S_{u} g(x)>0\right\} .
$$

Proof. For $f \in L_{1}$, let $\bar{f}(x)=S_{1} f(x)$. For each $u>0$, write $u=$ $n+r$, where $n=[u], 0 \leqq r<1$. Writing $T$ for $T_{1}$, we have

$$
\begin{aligned}
S_{u} f & =\int_{0}^{u} T_{t} f d t=\sum_{k=0}^{n-1} \int_{k}^{k+1} T_{t} f d t+\int_{n}^{n+r} T_{t} f d t \\
& =\sum_{k=0}^{n-1} T^{k} \int_{0}^{1} T_{t} f d t+T^{n} \int_{0}^{r} T_{t} f d t
\end{aligned}
$$

and hence

$$
S_{u} f(x)=\sum_{k=0}^{n-1} T^{k} \bar{f}(x)+T^{n}\left(S_{r} f\right)(x) .
$$

We may assume that $f$ is nonnegative; then $0 \leqq S_{r} f(x) \leqq \bar{f}(x)$ and $0 \leqq S_{r} g(x) \leqq \bar{g}(x)$ a.e., $0 \leqq r \leqq 1$. Thus, for $u$ sufficiently large, we have on $A(g)$

$$
\frac{\sum_{k=0}^{n-1} T^{k} \bar{f}(x)}{\sum_{k=0}^{n} T^{k} \bar{g}(x)} \leqq D_{u}(f, g)(x) \leqq \frac{\sum_{k=0}^{n} T^{k} \bar{f}(x)}{\sum_{k=0}^{n-1} T^{k} \bar{g}(x)} .
$$

This completes the proof, since the Chacon-Ornstein theorem and Lemma 2 [4] imply that the first and last terms in (2.3) converge to the same finite limit on the set $\left\{x: \sum_{k=0}^{\infty} T^{k} \bar{g}(x)>0\right\}=A(g)$.

For a bounded semi-group $\Gamma$, we have the following decomposition of the space $X$. 
Proposition 2.1. Let $\Gamma=\left\{T_{t}: t \geqq 0\right\}$ be a bounded semi-group of positive linear operators in $L_{1}$. Then the space $X$ decomposes into $Y$ and $Z$ with the following properties: $Z$ is $T_{t}$-closed for $t \geqq 0$;

$$
\left\{\begin{array}{l}
0 \neq \equiv \in L_{1}^{+}(Y) \text { implies } \liminf _{t \rightarrow \infty} \int T_{t} f d \mu>0 \\
f \in L_{1}(Z) \text { implies } \lim _{t \rightarrow \infty} \int T_{t}|f| d \mu=0 .
\end{array}\right.
$$

Proof. This result in the discrete parameter case was obtained by the second author in [11]. To prove the proposition, we apply the discrete case result to $T=T_{1}$, obtaining the decomposition $X=$ $Y+Z$ with the properties

$$
\left\{\begin{array}{l}
0 \neq \equiv f \in L_{1}^{+}(Y) \text { implies } \liminf _{n \rightarrow \infty} \int T_{n} f d \mu>0 ; \\
f \in L_{1}(Z) \text { implies } \lim _{n \rightarrow \infty} \int T_{n}|f| d \mu=0 .
\end{array}\right.
$$

Suppose that $f \in L_{1}^{+}$and $\liminf _{t \rightarrow \infty} \int T_{t} f d \mu=0$; then given $\varepsilon \in 0$, there is an $s>0$ such that $0 \leqq \int T_{s} f d \mu<\varepsilon$. For $t>s$, we have

$$
\begin{aligned}
0 & \leqq \int T_{t} f d \mu=\int T_{t-s}\left(T_{s} f\right) d \mu \\
& \leqq\left|T_{t-s}\right|_{1} \cdot\left|T_{s} f\right|_{1} \leqq \varepsilon \cdot \sup _{t \geqq 0}\left|T_{t}\right|_{1},
\end{aligned}
$$

which shows that $\lim _{t \rightarrow \infty} \int T_{t} f d \mu=0$; in view of (2.5), (2.4) is now proved. That $Z$ is $T_{t}$-closed for each $t \geqq 0$ is an easy consequence of (2.4).

The next proposition permits us to construct a semi-group $\Gamma^{\prime}$ of positive linear contractions related to $\Gamma$; the ratio ergodic properties of $\Gamma$ are then studied via $\Gamma^{\prime}$.

Proposition 2.2. Let $\Gamma=\left\{T_{t}: t \geqq 0\right\}$ be a bounded semi-group of positive linear operators in $L_{1}$, strongly continuous on $(0, \infty)$. Then there is a function $e$ such that

$$
e \in L_{\infty}^{+}, \operatorname{supp} e=Y, T_{t}^{*} e=e \text { for } t>0 .
$$

Proof. We may assume that $Y \neq \phi$ for otherwise the proposition is obviously true. Let 


$$
\begin{aligned}
& H=\left\{h \in L_{\infty}: T_{t}^{*} h=h, t>0\right\} ; \\
& D=\left\{1 / 2^{n}: n=0,1,2, \cdots\right\} \\
& G=\left\{g: g=f-T_{r} f, f \in L_{1}, r \in D\right\}
\end{aligned}
$$

Let $\operatorname{sp}(G)$ denote the linear span of $G$. We first show that $H \neq\{0\}$. Let $h \in L_{\infty}$ be such that $\int g \cdot h d \mu=0$ for every $g \in \operatorname{sp}(G)$. It follows from $\int\left(f-T_{r} f\right) \cdot h=0$, holding for each $f \in L_{1}, r \in D$, that

$$
T_{r}^{*} h=h, r \in D \text {. }
$$

The strong continuity of $\Gamma$ on $(0, \infty)$ now implies that (2.7) holds for any $r>0$. Assume $a b$ contrario that $H=\{0\}$; then $h=0$, and $s p(G)$ is dense in $L_{1}$. Thus given $f \in L_{1}^{+}(Y)$, and $\varepsilon>0$, there is a function $g \in \operatorname{sp}(G)$ such that $|f-g|_{1}<\varepsilon$. We note that $g$ is a linear combination of functions of the form $f_{j}-T_{r_{j}} f_{j}$, where $f_{j} \in L_{1}, r_{j} \in D$, $1 \leqq j \leqq m$; hence letting $r=\min \left\{r_{1}, r_{2}, \cdots, r_{m}\right\}$, we have

$$
\lim _{n} n^{-1} \cdot\left|\sum_{i=0}^{n-1} T_{r}^{i} g\right|_{1}=0 \text {. }
$$

Thus

$$
\begin{aligned}
\liminf _{n}\left|T_{r}^{n} f\right|_{1} & \leqq \limsup _{n} n^{-1} \cdot\left|\sum_{i=0}^{n-1} T_{r}^{i} f\right|_{1} \\
& \leqq \lim _{n} n^{-1}\left|\sum_{i=0}^{n-1} T_{r}^{i} g\right|_{1}+\varepsilon \cdot \sup _{t}\left|T_{t}\right|_{1} \\
& =\varepsilon \cdot \sup \left|T_{t}\right|_{1} .
\end{aligned}
$$

This contradicts relation (2.4) and the assumption $Y \neq \phi$, since $\varepsilon>0$ is arbitrary and $\Gamma$ is bounded. Now let $0 \neq h \in H$ and write $h=$ $h^{+}-h^{-}$, where $h^{+}=\max (h, 0), h^{-}=-\min (h, 0)$. We may assume $h^{+} \neq 0$; otherwise we replace $h$ by $-h$. We have $T_{t}^{*} h^{+} \geqq h^{+}$for $t>$ 0 . Let $h^{\prime}=\lim _{n} T_{n}^{*} h^{+}$; clearly, $0 \neq h^{\prime} \in L_{\infty}^{+}$and, by the monotone continuity of $T_{r}^{*}$ (cf. [9], p. 187), we have $T_{r}^{*} h^{\prime}=h^{\prime}$ for $r \in D$. It now follows from the strong continuity of $\Gamma$ that $T_{t}^{*} h^{\prime}=h^{\prime}$ for $t>$ 0 . Let $\pi$ be a probability measure equivalent with $\mu$, and let $s$ be the supremum of numbers $\pi(\operatorname{supp} h)$ where $h$ ranges over $H^{+}$, the class of nonnegative functions in $H$. There exists a sequence of functions $h_{n} \in H^{+}$with $\pi\left(\operatorname{supp} h_{n}\right) \rightarrow s$. If $e \in L_{\infty}^{+}$is a proper linear combination of the $h_{n}$ 's, and $E=\operatorname{supp} e$, then $e \in H^{+}, E \subset Y$ and $\pi(E)=s$. We next show that $E=Y$. We note that $E$ is $T_{t}^{*}$-closed, $t>0$. Indeed, there are functions $f_{n} \uparrow 1_{E}$ and constants $c_{n}>0$ such that $c_{n} f_{n} \leqq e$. Hence $\left(\operatorname{supp} T_{t}^{*} f_{n}\right) \subset E$, and by the monotone continuity of $T_{t}^{*},\left(\operatorname{supp} T_{t}^{*} 1_{E}\right) \subset E$. Applying the duality relation we can 
now see that $E^{c}=X-E$ is $T_{t}$-closed, $t>0$. If $T_{t}^{\prime}$ is the restriction of $T_{t}$ to $L_{1}\left(E^{c}\right)$, then $\Gamma^{\prime}=\left\{T_{t}^{\prime}: t \geqq 0\right\}$ is a semi-group of positive linear operators in $L_{1}$, strongly continuous on $(0, \infty)$. Under $\Gamma^{\prime}, E^{c}$ decomposes into sets $Y^{\prime}$ and $Z^{\prime}$ according to Proposition 2.1. Since $E^{c}$ is closed under $T_{t}$ for $t>0$, we have $\int T_{t}^{\prime} f d \mu=\int T_{t} f d \mu$ for $f \in L_{1}\left(E^{c}\right)$ and $t>0$. Hence $f \in L_{1}(Z)$ implies $\lim _{t} \int T_{t}^{\prime}|f| d \mu=\lim _{t} \int T_{t}|f| d \mu=0$, and $0 \not \equiv f \in L_{1}^{+}(Y-E)$ implies $\lim \inf _{t} \int T_{t}^{\prime} f d \mu=\liminf _{t} \int T_{t} f d \mu>0$. Consequently, $Y^{\prime}=Y-E$ and $Z^{\prime}=Z$. Thus if $E \neq Y$, then $Y^{\prime}$ is nonnull, and hence the first part of the proof, with $\Gamma^{\prime}$ replacing $\Gamma$, shows that there is a function $e_{1}, 0 \not \equiv e_{1} \in L_{\infty}^{+}\left(E^{c}\right)$, and $T_{t}^{*} e_{1} \geqq e_{1}, t>$ 0 . Since $T_{t}^{*} e_{1}=1_{E^{c}} \cdot T_{t}^{*} e_{1}$, we have $T_{t}^{*} e_{1} \geqq e_{1}, t>0$. Let $e^{\prime}=\lim _{n} T_{n}^{*} e_{1}$; then $e^{\prime} \in H^{+}$and $\left(\operatorname{supp} e^{\prime}\right) \cap E^{c}$ is nonnull. Thus $e+e^{\prime} \in H^{+}$and $\pi\left(\operatorname{supp}\left(e+e^{\prime}\right)\right)>s$, which contradicts the definition of $s$. Hence supp $e=Y$ and the proposition is proved.

Assume that $\Gamma=\left\{T_{t}: t \geqq 0\right\}$ satisfies the hypothesis of Proposition 2.2. Let $e$ be a solution of (2.6); we may assume that $0<e \leqq 1$ on $Y$. $T_{t}$ may be extended to a positive linear map on $\mathscr{M}^{+}$, the cone of nonnegative measurable functions on $(X, \mathscr{A})$ : for each fixed $t \geqq$ 0 , if $f \in \mathscr{L}^{+}, T_{t} f$ is defined as $\lim _{n} T_{t} f_{n}$ where $f_{n} \in L_{1}^{+}$, and $f_{n} \uparrow f$ a.e. The extended operators $T_{t}$ also satisfy the semi-group property on $\mathscr{H}^{+}$; i.e.,

$$
T_{t+s} f=T_{t}\left(T_{s} f\right), f \in \mathscr{M}^{+}, t, s \geqq 0 \text {. }
$$

For each $t \geqq 0$, we define an operator $V_{t}$ on $L_{1}^{+}$by the relation

$$
V_{t} f=e \cdot T_{t}\left(f /\left(e+1_{z}\right)\right),
$$

and extend $V_{t}$ by linearity to $L_{1}$. One shows, as in [11], that $\Gamma^{\prime}=$ $\left\{V_{t}: t \geqq 0\right\}$ is a family of positive linear contractions in $L_{1}$. That $\Gamma^{\prime}$ is a semi-group is a consequence of (2.9), (2.10), and the fact that $Z$ is $T_{t}$-closed, $t \geqq 0$. Let $K=\left\{g: g=f \cdot e, f \in L_{1}\right\}$. For a fixed $s>0$ and $g=f \cdot e \in K, f \in L_{1}$, we have

$$
\begin{aligned}
\left|V_{t} g-V_{s} g\right|_{1} & =\left|e \cdot T_{t}\left(\frac{g}{e+1_{Z}}\right)-e \cdot T_{s}\left(\frac{g}{e+1_{Z}}\right)\right|_{1} \\
& \leqq|e|_{\infty} \cdot\left|T_{t}\left(f \cdot 1_{Y}\right)-T_{s}\left(f \cdot 1_{Y}\right)\right|_{1}
\end{aligned}
$$

which, by the strong continuity of $\Gamma$, tends to zero as $t \rightarrow s$. The case of a general $g \in L_{1}(Y)$ follows by approximation, since $K$ is a dense subspace of $L_{1}(Y)$ and $\left|V_{t}\right|_{1} \leqq 1$. Finally, because $V_{t} g=V_{t}\left(g \cdot 1_{Y}\right)$ for $g \in L_{1}$, we conclude that $\Gamma^{\prime}$ is strongly continuous on $(0, \infty)$. 
Theorem 2.1 may now be applied to $\Gamma^{\prime}$ : if $f^{\prime} \in L_{1}^{+}, g^{\prime} \in L_{1}^{+}$, then

$$
\lim _{u \rightarrow \infty} \int_{0}^{u} V_{t} f^{\prime}(x) d t / \int_{0}^{u} V_{t} g^{\prime}(x) d t
$$

exists a.e. on the set $\left\{x: \sup _{u>0} \int_{0}^{u} V_{t} g^{\prime}(x) d t>0\right\}$. For arbitrary measurable nonnegative functions $f$ and $g$, we write $f^{\prime}=f \cdot e, g^{\prime}=g \cdot e$. If $f^{\prime} \in L_{1}^{+}, g^{\prime} \in L_{1}^{+}$, then for sufficiently large $u$,

$$
\frac{\int_{0}^{u} V_{t} f^{\prime}(x) d t}{\int_{0}^{u} V_{t} g^{\prime}(x) d t}=\frac{\int_{0}^{u} e(x) \cdot T_{t} f(x) d t}{\int_{0}^{u} e(x) \cdot T_{t} g(x) d t}=D_{u}(f, g)(x)
$$

on $Y \cap A(g)$, where $A(g) \stackrel{\text { def }}{=}\left\{x: \sup _{u>0} S_{u} g(x)>0\right\}$. Thus the last ratio in (2.12) converges to a finite limit a.e. on the set $Y \cap A(g)$. The above discussion is now summarized in the following theorem:

THEOREM 2.2. Let $\Gamma=\left\{T_{t}: t \geqq 0\right\}$ be a bounded semi-group of positive linear operators in $L_{1}$, storongly continuous on $(0, \infty)$. If $f$, $g$ are measurable functions such that $f \cdot e, g \cdot e \in L_{1}^{+}$, then $\lim _{u \rightarrow \infty}\left(D_{u}(f, g)(x)\right.$ exists a.e. on the set $Y \cap A(g)$.

We say that the ratio theorem holds (for $\Gamma$ ) on a subset $B$ of $X$ if whenever $f \in L_{1}, g \in L_{1}^{+}, \lim _{u \rightarrow \infty} D_{u}(f, g)(x)$ exists a.e. on the set $B \cap A(g)$; otherwise we say that the ratio theorem fails on $B$. We showed that the ratio theorem holds on $Y$. We now show

THEOREM 2.3. Let $\Gamma=\left\{T_{t}: t \geqq 0\right\}$ be bounded semi-group of positive linear operators in $L_{1}$, strongly continuous on $(0, \infty)$. If there is a function $g \in L_{1}^{+}(Z)$ such that the set $C(g) \stackrel{\text { def }}{=}\left\{x: \sup _{u>0} S_{u} g(x)=\infty\right\}$ is nonnull, then the ratio theorem fails on every nonnull subset of $C(g)$.

Proof. Theorem 2.3 in the discrete parameter case was given in [7]; (see also [11] and [6]). The method of proof in [7] extends to the continuous case. Assume that the ratio theorem holds on a nonnull subset $A$ of $C(g)$, where $g \in L_{1}^{+}(Z)$. In particular, $\lim _{u \rightarrow \infty} D_{u}(f, g)(x)$ exists a.e., on $A$ for every $f \in L_{1}$. Let $R$ be the operator from $L_{1}$ into $\mathscr{A}$, the space of real-valued measurable functions on $(X, \mathscr{A})$, defined by $R f(x)=1_{A}(x) \cdot \lim _{u \rightarrow \infty} D_{u}(f, g)(x)$. Since $S_{u} g(x) \rightarrow \infty$ on $A$, we have for each $t>0$ 


$$
\begin{aligned}
R\left(T_{t} g\right)(x) & =\lim _{u \rightarrow \infty} \frac{\int_{0}^{u} T_{s+t} g(x) d s}{\int_{0}^{u} T_{s} g(x) d s} \\
& =\lim _{u \rightarrow \infty}\left[\frac{\int_{0}^{u} T_{s} g(x) d s}{\int_{0}^{u} T_{s} g(x) d s}-\frac{\int_{0}^{t} T_{s} g(x) d s}{\int_{0}^{u} T_{s} g(x) d s}+\frac{\int_{u}^{u+t} T_{s} g(x) d s}{\int_{0}^{u} T_{s} g(x) d s}\right] \geqq 1
\end{aligned}
$$

on $A$. On the other hand, since $\left|T_{t} g\right|_{1} \rightarrow 0$ as $t \rightarrow \infty$, we may choose a subsequence $\left(T_{t_{n}} g\right)$ with $\sum_{n=1}^{\infty} T_{t_{n}} g \in L_{1}$. Then $0 \leqq \sum_{n=1}^{\infty} R\left(T_{t_{n}} g\right) \leqq$ $R\left(\sum_{n=1}^{\infty} T_{t_{n}} g\right)<\infty \mu$-a.e.; hence $\lim _{n} R\left(T_{t_{n}} g\right)=0 \mu$-a.e., but this contradicts (2.13).

3. Local behavior. Akcoglu and Chacon [1] have shown that for a semi-group $\Gamma=\left\{T_{t}: t \geqq 0\right\}$ of positive linear contractions in $L_{1}(X, \mathscr{A}, \mu)$, there is a decomposition of the space $X$ into an 'initially conservative part', $C$, and 'initially dissipative part', $D$. The set $C$ may be defined as $\left\{x: S_{u} f(x)>0\right.$ for all $\left.u>0\right\}$, where $f$ is any strictly positive function in $L_{1}(X, \mathscr{A}, \mu)$. We note that this decomposition remains valid for bounded semi-groups. The main result in [1] can be stated as follows:

THEOREM A. Let $\Gamma=\left\{T_{t}: t \geqq 0\right\}$ be a semi-group of positive linear contractions in $L_{1}(X, \mathscr{A}, \mu)$, strongly continuous on $(0, \infty)$. If $\in L_{1}, g f \in L_{1}^{+}$, then $\lim _{u \downarrow}\left(S_{u} f(x)\right) /\left(S_{u} g(x)\right)$ exists a.e. on the set $C \cap\{g>0\}$.

We recall from $\S 2$ that for a bounded semi-group $\Gamma=\left\{T_{t}: t \geqq 0\right\}$ of positive linear operators in $L_{1}$, strongly continuous on $(0, \infty)$, we can construct a semi-group $\left.\Gamma^{\prime}=V_{t}: t \geqq 0\right\}$ of positive linear contractions related to $\Gamma$ defined by (2.10). Theorem A is thus applicable to $\Gamma^{\prime}$. Let $X=C+D=C^{\prime}+D^{\prime}$ be the initial decompositions corresponding to $\Gamma$ and $\Gamma^{\prime}$ respectively.

Theorem A applied to $\Gamma^{\prime}$ shows that if $f^{\prime} \in L_{1}, g^{\prime} \in L_{1}^{+}$, then $\lim _{u \downarrow \circ} \int_{0}^{u} V_{s} f^{\prime}(x) d s / \int_{0}^{u} V_{s} g^{\prime}(x) d s$ exists a.e. on the set $C^{\prime} \cap\left\{g^{\prime}>0\right\}$. For arbitrary measurable nonnegative functions $f$ and $g$, we let $f^{\prime}=f \cdot e$, $g^{\prime}=g \cdot e$. If $f^{\prime}, g^{\prime} \in L_{1}^{+}$, then

$$
\frac{\int_{0}^{u} V_{s} f^{\prime}(x) d s}{\int_{0}^{u} V_{s} g^{\prime}(x) d s}=\frac{e(x) \cdot \int_{0}^{u} T_{s} f(x) d s}{e(x) \cdot \int_{0}^{u} T_{s} g(x) d s}=\frac{S_{u} f(x)}{S_{u} g(x)}
$$

on the set $\left\{x: \int_{0}^{u} V_{s} g^{\prime}(x) d s>0\right.$ for $\left.u>0\right\}$, which contains the set $C^{\prime} \cap$ 
$\left\{g^{\prime}>0\right\}$, as shown in [1], Lemma 2.3. Thus $\lim _{u \downarrow} \circ\left(S_{u} f(x)\right) /\left(S_{u} g(x)\right)$ exists a.e., on the set $C^{\prime} \cap\left(g^{\prime}>0\right\}$.

It is clear from $g^{\prime}=g \cdot e$ that $\left\{g^{\prime}>0\right\}=\{g>0\} \cap Y$. We next show that $C^{\prime}=C \cap Y$. Let $C$ be defined in terms of some fixed function $g \in L_{1}, g>0$. For each $u>0$,

$$
\int_{0}^{u} T_{s} g(x) d s=\int_{0}^{u} T_{s} g_{Y}(x) d s+\int_{0}^{u} T_{s} g_{Z}(x) d s .
$$

The last integral in (3.2) vanishes a.e. on $Y$ since $Z$ is $T_{s}$-closed, $s \geqq 0$. Hence $\int_{0}^{u} T_{s} g(x) d s=\int_{0}^{u} T_{s} g_{Y}(x) d s>0$ on $C \cap Y$. Let $g^{\prime}=g_{Y} \cdot e$. Then $\int_{0}^{u} V_{s} g^{\prime}(x) d s=e(x) \cdot \int_{0}^{u} T_{s} g_{Y}(x) d s>0$ for $u>0$ on $C \cap Y$. This shows that $C^{\prime} \supset C \cap Y$. Next, since $V_{s} g(x)=0$ a.e. on $Z$ for any $g \in L_{1}$, $C^{\prime}$ may be obtained as the set $\left\{x: \int_{0}^{u} V_{s} g(x) d s>0\right.$ for $\left.u>0\right\}$ for any $g \in L_{1}^{+}$such that $g>0$ on $Y$. Let $g^{\prime}=g \cdot e$. Then $g^{\prime}>0$ on $Y$ and hence $\int_{0}^{u} V_{s} g^{\prime}(x) d s>0$ on $C^{\prime}, u>0$. Since $\int_{0}^{u} V_{s} g^{\prime}(x) d s=\int_{0}^{u} e(x) \cdot T_{s} g(x) d s$, we conclude that $\int_{0}^{u} T_{s} g(x) d s>0$ a.e. on $C^{\prime}, u>0$. Hence $C^{\prime} \subset C \cap Y$. We have proved:

TheOREM 3.1. Let $\Gamma=\left\{T_{t}: t \geqq 0\right\}$ be a bounded semi-group of positive linear operators in $L_{1}$, strongly continuous on $(0, \infty)$. If $f, g$ are nonnegative measurable functions such that $f \cdot e, g \cdot e \in L_{1}^{+}$, then $\left.\lim _{u \downarrow \circ}\left(S_{u} f(x)\right) / S_{u} g(x)\right)$ exists a.e. on the set $\{g>0\} \cap C \cap Y$.

Of course, the restriction of the above statement to $C$ is not a loss of generality, since on $D$ the ratio $D_{u}$ is of the form $0 / 0$. The local behavior of $D_{u}$ on $Z$ does not seem to be easy to ascertain by the methods of the present paper.

\section{REFERENCES}

1. M. A. Akcoglu and R. V. Chacon, A local ratio theorem, To appear.

2. M. A. Akcoglu and J. Cunsolo, An ergodic theorem for semi-groups, To appear in Proc. Amer. Math. Soc.

3. K. N. Berk, Ergodic theory with weighted averages., Ann. Math. Sta., 39 (1968). 1107-1114.

4. R. V. Chacon and D, S. Ornstein, A general ergodic theorem, Illinois J. Math., 4 (1960), 153-160.

5. N. Dunford and J. T. Schwartz, Linear Operators $I$, New York, Interscience Publ. 1966.

6. H. Fong, On invariant functions for $L_{p}$-operators, To appear in Colloquium Mathematicum, XXII.

7. A. Ionescu Tulcea and M. Moretz, Ergodic properties of semi-Markovian operators on the Z-part. Z. Wahrscheinlichkeitstheorie verw. Geb., 13 (1969), 119-122.

8. U. Krengel, A local ergodic theorem, To appear. 
9. J. Neveu, Mathematical Foundations of the calculus of probability, San Francisco: Holden-Day, Inc. 1965.

10. D. S. Ornstein, The sums of iterates of a positive operator, To appear.

11. L. Sucheston, On the ergodic theorem for positive operators I. II, Z. Wahrscheinlichkeitstheorie verw. Geb., 8 (1967), 1-11, 353-356.

Received January 26, 1970. This research was supported by the NSF Grant GP13692.

The University of Michigan

Bowling Green State University

AND

The Ohio State University 



\title{
PACIFIC JOURNAL OF MATHEMATICS
}

\author{
EDITORS
}

\author{
H. SAMELSON \\ Stanford University \\ Stanford, California 94305 \\ C. R. HOBBY \\ University of Washington \\ Seattle, Washington 98105
}

J. DugundJI

Department of Mathematics

University of Southern California

Los Angeles, California 90007

RICHARD ARENS

University of California

Los Angeles, California 90024

\section{ASSOCIATE EDITORS}
E. F. BeCKenBaCH
B. H. NeUMANN
F. WOLF
K. Yoshida

\section{SUPPORTING INSTITUTIONS}

\author{
UNIVERSITY OF BRITISH COLUMBIA \\ CALIFORNIA INSTITUTE OF TECHNOLOGY \\ UNIVERSITY OF CALIFORNIA \\ MONTANA STATE UNIVERSITY \\ UNIVERSITY OF NEVADA \\ NEW MEXICO STATE UNIVERSITY \\ OREGON STATE UNIVERSITY \\ UNIVERSITY OF OREGON \\ OSAKA UNIVERSITY
}

\author{
UNIVERSITY OF SOUTHERN CALIFORNIA \\ STANFORD UNIVERSITY \\ UNIVERSITY OF TOKYO \\ UNIVERSITY OF UTAH \\ WASHINGTON STATE UNIVERSITY \\ UNIVERSITY OF WASHINGTON \\ AMERICAN MATHEMATICAL SOCIETY \\ NAVAL WEAPONS CENTER
}

The Supporting Institutions listed above contribute to the cost of publication of this Journal, but they are not owners or publishers and have no responsibility for its content or policies.

Mathematical papers intended for publication in the Pacific Journal of Mathematics should be in typed form or offset-reproduced, (not dittoed), double spaced with large margins. Underline Greek letters in red, German in green, and script in blue. The first paragraph or two must be capable of being used separately as a synopsis of the entire paper. The editorial "we" must not be used in the synopsis, and items of the bibliography should not be cited there unless absolutely necessary, in which case they must be identified by author and Journal, rather than by item number. Manuscripts, in duplicate if possible, may be sent to any one of the four editors. Please classify according to the scheme of Math. Rev. Index to Vol. 39. All other communications to the editors should be addressed to the managing editor, Richard Arens, University of California, Los Angeles, California, 90024.

50 reprints are provided free for each article; additional copies may be obtained at cost in multiples of 50 .

The Pacific Journal of Mathematics is published monthly. Effective with Volume 16 the price per volume (3 numbers) is $\$ 8.00$; single issues, $\$ 3.00$. Special price for current issues to individual faculty members of supporting institutions and to individual members of the American Mathematical Society: $\$ 4.00$ per volume; single issues $\$ 1.50$. Back numbers are available.

Subscriptions, orders for back numbers, and changes of address should be sent to Pacific Journal of Mathematics, 103 Highland Boulevard, Berkeley, California, 94708.

PUBLISHED BY PACIFIC JOURNAL OF MATHEMATICS, A NON-PROFIT CORPORATION

Printed at Kokusai Bunken Insatsusha (International Academic Printing Co., Ltd.), 270, 3chome Totsuka-cho, Shinjuku-ku, Tokyo 160, Japan. 


\section{Pacific Journal of Mathematics}

\section{Vol. 39, No. $3 \quad$ July, 1971}

William O'Bannon Alltop, 5-designs in affine spaces ................... 547

B. G. Basmaji, Real-valued characters of metacyclic groups ................. 553

Miroslav Benda, On saturated reduced products....................... 557

J. T. Borrego, Haskell Cohen and Esmond Ernest Devun, Uniquely representable semigroups. II.......................................

George Lee Cain Jr. and Mohammed Zuhair Zaki Nashed, Fixed points and stability for a sum of two operators in locally convex spaces ....................

Donald Richard Chalice, Restrictions of Banach function spaces ...............

Eugene Frank Cornelius, Jr., A generalization of separable groups ..............

Joel L. Cunningham, Primes in products of rings ......................

Robert Alan Morris, On the Brauer group of $Z$.

593

603

615

David Earl Dobbs, Amitsur cohomology of algebraic number rings ...............

Charles F. Dunkl and Donald Edward Ramirez, Fourier-Stieltjes transforms and

weakly almost periodic functionals for compact groups ...................

Hicham Fakhoury, Structures uniformes faibles sur une classe de cônes et

d'ensembles convexes ......................................

Leslie R. Fletcher, A note on C $\theta \theta$-groups.

Humphrey Sek-Ching Fong and Louis Sucheston, On the ratio ergodic theorem for

semi-groups............................................

James Arthur Gerhard, Subdirectly irreducible idempotent semigroups ...........

Thomas Eric Hall, Orthodox semigroups.....................

Marcel Herzog, $C \theta \theta$-groups involving no Suzuki groups ..........

669

687

John Walter Hinrichsen, Concerning web-like continua ..........

691

Frank Norris Huggins, A generalization of a theorem of F. Riesz.

695

Carlos Johnson, Jr., On certain poset and semilattice homomorphisms

703

Alan Leslie Lambert, Strictly cyclic operator algebras ...........

717

Howard Wilson Lambert, Planar surfaces in knot manifolds . . .

727

Robert Allen McCoy, Groups of homeomorphisms of normed linear spaces ....... 735

T. S. Nanjundiah, Refinements of Wallis's estimate and their generalizations ...... 745

Roger David Nussbaum, A geometric approach to the fixed point index .......... 751

John Emanuel de Pillis, Convexity properties of a generalized numerical range .... 767

Donald C. Ramsey, Generating monomials for finite semigroups ....

783

William T. Reid, A disconjugacy criterion for higher order linear vector differential equations...

Roger Allen Wiegand, Modules over universal regular rings...

Kung-Wei Yang, Compact functors in categories of non-archimedean Banach

spaces.

R. Grant Woods, Correction to: "Co-absolutes of remainders of Stone-Čech compactifications".

Ronald Owen Fulp, Correction to: "Tensor and torsion products of

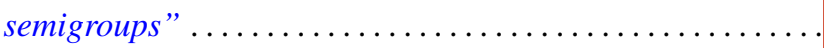

Bruce Alan Barnes, Correction to: "Banach algebras which are ideals in a banach 